\title{
Aspectos da natureza da ciência em pesquisas científicas divulgadas em eventos nacionais
}

O presente trabalho teve como objetivo realizar uma análise dos trabalhos publicados em anais nas edições do Congresso Nacional de Educação (CONEDU) e do Congresso Nacional de Pesquisa e Ensino em Ciências (CONAPESC) sobre o tema Natureza da Ciência (NdC). Para isso, as sete edições do CONEDU (2014 - 2020) e as cinco edições do CONAPESC (2016-2020) foram investigadas por completo na busca dos trabalhos para análise. Para a seleção dos artigos utilizou-se como critérios: conter expressamente no título e/ou nas palavras-chave do trabalho a expressão 'natureza da ciência' associada a 'educação científica'. Posteriormente, os trabalhos encontrados passaram por uma leitura e exploração criteriosa, favorecendo uma análise e interpretações dos dados produzidos. Por meio deste estudo, percebeu-se um ínfimo número de pesquisas envolvendo a temática natureza da ciência ao longo das edições do CONEDU e CONAPESC. Diante disto, almeja-se que as produções desenvolvidas pelos autores e autoras, aqui divulgadas e discutidas, subsidiem o fortalecimento das discussões sobre a NdC e a sua inserção no contexto educacional.

Palavras-chave: Natureza da Ciência; Educação Científica; Produções Científicas; CONEDU; CONAPESC.

\section{Aspects of the nature of science in scientific research published at national events}

\begin{abstract}
The present work had as objective to carry out an analysis of the works published in the annals in the editions of Congresso Nacional de Educação (CONEDU) and Congresso Nacional de Pesquisa e Ensino em Ciências (CONAPESC) on the theme Nature of Science (NdC). For this, the seven editions of CONEDU (2014 - 2020) and the five editions of CONAPESC (2016-2020) were fully investigated in search of works for analysis. For the selection of articles, the following criteria were used: expressly contain in the title and/or keywords of the work the expression 'nature of science' associated with 'scientific education'. Subsequently, the works found underwent a careful reading and exploration, favoring an analysis and interpretation of the data produced. Through this study, a small number of researches involving the thematic nature of science were noticed throughout the editions of CONEDU and CONAPESC. In view of this, it is hoped that the productions developed by the authors and authors, published and discussed here, support the strengthening of discussions about the $\mathrm{NdC}$ and its insertion in the educational context.
\end{abstract}

Keywords: Nature of Science; Scientific Education; Scientific Productions; CONEDU; CONAPESC.

Topic: Ensino de Ciências e Matemática

Reviewed anonymously in the process of blind peer.
Received: $19 / 04 / 2021$

Approved: 20/07/2021
Jardenson Ferreira de Freitas (iD)

Universidade do Estado do Rio Grande do Norte, Brasi

http://lattes.cnpq.br/2938128035375592

http://orcid.org/0000-0003-2109-0829

jardenson.ferreira@gmail.com

Daniele Bezerra dos Santos (iD)

Instituto Federal do Rio Grande do Norte, Brasil

http://lattes.cnpq.br/5283796635348667

http://orcid.org/0000-0001-7896-6946

danielebezerrabio@gmail.com

Clécio Danilo Dias da Silva

Universidade do Estado do Rio Grande do Norte, Brasil http://lattes.cnpq.br/4235157508528733

http://orcid.org/0000-0002-7776-8830

danilodiass18@gmail.com
Referencing this:

FREITAS, J. F.; SANTOS, D. B.; SILVA, C. D. D.. Aspectos da natureza da ciência em pesquisas científicas divulgadas em eventos nacionais. Educationis, v.9, n.2, p.64-69, 2021. DOI: http://doi.org/10.6008/CBPC2318-3047.2021.002.0008 


\section{INTRODUÇÃO}

Atualmente, dentro do panorama científico, a área educacional vem buscando alguns avanços, especialmente, no que tange ao entendimento da Ciência no contexto filosófico e epistemológico (LIMA, 2019). Conforme Moura (2014) o propósito de fazer com que estudantes e professores aprendam e ensinem não somente Ciência, mas também sobre a Ciência, tem se estabelecido num objetivo ambicionado por diversos educadores, formadores e acadêmicos.

Em um contexto histórico da educação científica, trabalhos observaram que existia a formação de um conceito de ciência pura, conteudista e formatada em um painel exato e concreto (LIMA, 2019; MENDONÇA, 2020). De modo inverso, hoje vemos a construção da Ciência com um formato dinâmico e problematizador, constituindo uma realidade mutável e visualizando os erros como avanço científico (MOURA, 2014; MENDONÇA, 2020). É nessa concepção que surge a necessidade de compreender a "Natureza da Ciência" (NdC) para entender sobre a Ciência, que reflete sobre vários aspectos do que é, como é seu funcionamento, sua forma de construção e desenvolvimento, seus métodos e valores, relações e contribuições para a sociedade (LIMA, 2019).

A definição da NdC pode constituir-se em uma tarefa bastante complexa, uma vez que envolve os resultados de investigações das diversas áreas do saber, como a história, filosofia e sociologia das Ciências, além de ciências cognitivas, como a psicologia (SASSERON, 2018; MENDONÇA, 2020; MAIA et al., 2020). Contudo, Moura (2014) afirma que, de forma holística, a NdC pode ser entendida como um conjunto de elementos que versam sobre construção, estabelecimento e organização do conhecimento científico. "Isto pode abranger desde questões internas, tais como método científico e relação entre experimento e teoria, até outras externas, como a influência de elementos sociais, culturais, religiosos e políticos na aceitação ou rejeição de ideias científicas (MOURA, 2014).

Para Moura et al. (2016) a NdC ainda é um assunto pouco explorado no contexto educacional contemporâneo, mas que exerce importante contribuição para a educação científica. Complementando este pensamento, Maia et al. (2020) defendem que o desenvolvimento de conhecimentos sobre NdC é essencial para a promoção da educação científica, no sentido de desmitificar a Ciência, de forma a compreendê-la em seu contexto de produção e desenvolvimento, assim como entender as inúmeras relações estabelecidas nesse processo, como por exemplo, aquelas associadas a interesses, poder e tecnologia. Além disso, Goldbert et al. (2011) apontam que os conhecimentos apropriados pelos estudantes sobre NdC, impactaram tanto a própria visão sobre a Ciência quanto sobre o desenvolvimento do conhecimento de conteúdos científicos.

Diante deste contexto, considerando a relevância do Congresso Nacional de Educação (CONEDU) e do Congresso Nacional de Pesquisa e Ensino em Ciências (CONAPESC) para formação de estudantes, bem como, a consequente divulgação de estudos e pesquisas no âmbito nacional, o presente trabalho teve como objetivo realizar uma análise dos trabalhos publicados em anais nas edições do CONEDU e CONAPESC sobre o tema Natureza da Ciência. 


\section{METODOLOGIA}

O presente estudo pode ser classificado como pesquisa qualitativa, exploratória e de caráter bibliográfico. A pesquisa qualitativa busca explicar o significado e as características das informações do objeto de estudo em seu contexto histórico (ou estrutural) em uma perspectiva mais profunda. No tocante a pesquisa exploratória, um autor afirma que ela tem como objetivos explicitar um problema, empregando como procedimento a pesquisa bibliográfica a partir de pesquisa e levantamento de referenciais teóricos, leitura e fichamento do material.

Inicialmente, buscou-se nas páginas dos anais dos eventos todas as ocorrências possíveis para a temática Natureza da Ciência. As sete edições do CODENU (2014 - 2020) e cinco edições do CONAPESC (20162020) foram investigadas por completo na busca dos trabalhos para análise. Para a seleção dos artigos utilizou-se como critérios: conter expressamente no título e/ou nas palavras-chave do trabalho a expressão 'Natureza da Ciência'. Posteriormente, os trabalhos encontrados passaram por uma leitura e exploração criteriosa, favorecendo uma análise e interpretações dos dados produzidos.

\section{RESULTADOS E DISCUSSÃO}

Diante das analises efetivas, no Quadro 1 a seguir pode ser observado a expressividade e frequência das publicações envolvendo a temática Natureza da Ciência nas edições do CONAPESC e CONEDU.

Quadro 1: Expressividade das produções sobre a NdC nos eventos investigados.

\begin{tabular}{|c|c|c|c|c|}
\hline Evento & Edição/ano & & Total de Artigos & Artigos sobre $\mathrm{NdC}$ \\
\hline \multirow{5}{*}{ CONAPESC } & I EDIÇÃO & 2016 & 578 & 1 \\
\hline & II EDIÇÃO & 2017 & 915 & 1 \\
\hline & III EDIÇÃO & 2018 & 627 & 0 \\
\hline & IV EDIÇÃO & 2019 & 1005 & 0 \\
\hline & V EDIÇÃO & 2020 & 471 & 0 \\
\hline \multirow{7}{*}{ CONEDU } & I EDIÇÃO & 2014 & 1400 & 0 \\
\hline & II EDIÇÃO & 2015 & 2019 & 0 \\
\hline & III EDIÇÃO & 2016 & 2893 & 1 \\
\hline & IV EDIÇÃO & 2017 & 3991 & 1 \\
\hline & V EDIÇÃO & 2018 & 3887 & 1 \\
\hline & VI EDIÇÃO & 2019 & 5068 & 1 \\
\hline & VII EDIÇÃO & 2020 & 2236 & 0 \\
\hline
\end{tabular}

Como observado no Quadro 1, ao longo das cinco edições do CONAPESC foram publicados um total de 3.596 produções, entretanto apenas 02 envolviam o tema "Natureza da Ciência". Já o CONEDU, no decorrer de sete edições do foram publicados um total de 21.494 trabalhos, contudo, apenas 04 produções envolviam o tema da pesquisa. No Quadro 2 a seguir, está explicitado os artigos, autores e eventos para cada publicação encontrada. Posteriormente, são traçadas discussões entorno desses trabalhos.

O trabalho "Investigação da concepção dos alunos do ensino médio sobre os aspectos relacionados a Natureza da Ciência", de Conceição (2017), objetivou analisar a concepção dos estudantes do ensino médio do Instituto Federal de Educação, Ciência e Tecnologia do Maranhão - IFMA, sobre a Natureza da Ciência, verificando se houve mudanças significativas nas concepções dos alunos ao concluírem ensino médio. Para isso, os autores aplicaram questionários sobre a temática ( $\mathrm{NdC}$ ), em duas etapas: a primeira ao ingresso dos e das discentes na instituição e a segunda ao final do ensino médio. De forma geral, os autores verificaram 
que os estudantes investigados demonstraram não compreender adequadamente a Natureza da Ciência, devido à falta "de trabalhos" que abordassem a educação científica e a natureza da ciência ao longo da formação básica, o que fez com que estes apresentassem dificuldade na compreensão da origem, estrutura, métodos e validades do conhecimento científico. Assim, cientes da relevância deste tema, os autores afirmaram a necessidade de a implementação de práticas pedagógicas que possam desencadear competências e habilidades para garantir um ensino de qualidade e que atendam às necessidades dos alunos. "As análises da compreensão que estudantes possuem sobre a Natureza da Ciência é um estudo motivando a busca por mudanças no ensino de Ciência, contribuindo para a melhora de uma aprendizagem mais significativa (CONCEIÇÃO, 2017).

Quadro 2: Detalhamento das produções sobre a NdC nos eventos investigados.

\begin{tabular}{|l|l|l|}
\hline Autores & Título da produção & Evento/edição \\
\hline Conceição (2017) & $\begin{array}{l}\text { Investigação da concepção dos alunos do ensino médio sobre os aspectos relacionados a Natureza da } \\
\text { Ciência }\end{array}$ & $\begin{array}{l}\text { CONEDU } \\
\text { III EDIÇÃO }\end{array}$ \\
\hline $\begin{array}{l}\text { Moura et al. } \\
\text { (2016) }\end{array}$ & $\begin{array}{l}\text { Percepção dos bolsistas iniciação à docência do PIBID-Bio/FACEDI acerca da importância da abordagem } \\
\text { da Natureza da Ciência (NdC) }\end{array}$ & $\begin{array}{l}\text { CONEDU } \\
\text { III EDIÇÃO }\end{array}$ \\
\hline Moul et al. (2016) & $\begin{array}{l}\text { Visões sobre a natureza da ciência: comparando concepções sobre cientistas de estudantes da educação } \\
\text { básica }\end{array}$ & $\begin{array}{l}\text { CONAPESC } \\
\text { I EDIÇÃO }\end{array}$ \\
\hline Souza (2017) & Discussões recentes na literatura sobre a natureza da ciência & $\begin{array}{l}\text { CONAPESC } \\
\text { II EDIÇÃO }\end{array}$ \\
\hline $\begin{array}{l}\text { Ribeiro et al. } \\
\text { (2018) }\end{array}$ & Relação teoria e prática e Natureza da Ciência: percepções a partir da experiência no PIBID-BIO/FACEDI & $\begin{array}{l}\text { CONEDU } \\
\text { V EDIÇÃO }\end{array}$ \\
\hline Lima (2019) & A Natureza da Ciência e o ensino: investigando as percepções de futuros professores de química & $\begin{array}{l}\text { CONEDU } \\
\text { VI EDIÇÃO }\end{array}$ \\
\hline
\end{tabular}

O artigo "Percepção dos bolsistas iniciação à docência do PIBID-Bio/FACEDI acerca da importância da abordagem da Natureza da Ciência (NdC)" de Moura et al. (2016) teve como objetivo verificar a importância atribuída pelos bolsistas Programa Institucional de Bolsas de Iniciação à Docência, subprojeto na área da Biologia (PIBID-BIO), para a abordagem da NdC na educação científica e durante a formação docente. Os autores no desenvolvimento dos subprojetos partiram do pressuposto de que o papel dos docentes atuantes na educação básica é de formar discentes cada vez mais críticos sobre as questões tecnocientíficas, além de participantes ativos nos assuntos sócios-culturais. Os autores apontaram que a compreensão e abordagem sobre a NdC é basilar na formação docente, e que este fato se constitui de grande importância para reflexão durante a formação científica de futuros professores, que serão alfabetizadores científicos (MOURA et al., 2016).

O estudo "Visões sobre a natureza da ciência: comparando concepções sobre cientistas de estudantes da educação básica" de Moul et al. (2016), teve como objetivo realizar uma análise das concepções acerca da natureza da ciência, mais especificamente sobre o cientista, de alunos das séries finais do Ensino Fundamental II e do Ensino Médio de uma escola privada, a fim de comparar os seus discursos individuais e coletivos. Para isso, os pesquisadores leram para os estudantes investigados um texto sobre o que é a Ciência. Em seguida, foi solicitado aos discentes que escrevessem as suas visões sobre quem é o cientista, de forma individual. Posteriormente, os materiais produzidos pelos alunos foram estudados por meio da Análise do Discurso do Sujeito Coletivo (DSC). Com a pesquisa, os autores constataram a necessidade da modificação na estrutura das aulas de Ciências, em que os professores instiguem os alunos a interpretar e compreender os fenômenos naturais, refletindo sobre o papel da ciência que está associado aos benefícios produzidos para 
a sociedade, bem como, os efeitos colaterais que ocasionam problemas socioambientais. "Por esse motivo, os professores devem utilizar novas estratégias que levam construção da concepção de Ciência/Cientista mais coerente, em que se valorizam o trabalho cooperativo e os conhecimentos num processo contínuo de produção" (MOUL et al., 2016).

Souza (2017) no artigo "Discussões recentes na literatura sobre a natureza da ciência" teve como objetivo efetivar uma revisão narrativa e compreensiva de estudos e pesquisas sobre a NDC. No material, a autora discutiu as concepções de NDC presentes na literatura (conceituação e características), bem como, descreveu as propostas recentes apresentadas em trabalhos internacionais a respeito da NDC publicados nas duas últimas décadas, abordando seus aspectos mais relevantes. Em seguida, a autora, traçou algumas considerações sobre como a abordagem atual (Abordagem semelhança familiar) vêm sendo um caminho potencialmente produtivo para incorporar a NDC no ensino. Com relação a estrutura semelhança familiar, Souza (2017) afirma que ela abre oportunidades para incorporar, por exemplo, história da ciência, bem como modelos cognitivos para o raciocínio científico, para a concepção e avaliação de currículo unidades. A autora assegura que um currículo que incorpora as ideias da semelhança familiar promoverá aprendizagem entre alguns professores e pode promover o desenvolvimento de uma disposição para reflexão, entre outros. Assim, a "abordagem semelhança familiar também é atraente porque é filosoficamente neutra no sentido de que é livre de compromissos filosóficos como o realismo, o positivismo, o empirismo, o construtivismo, e similares" (SOUZA, 2017)

No artigo "Relação teoria e prática e Natureza da Ciência: percepções a partir da experiência no PIBIDBIO/FACEDI" de Ribeiro et al. (2018), discutiram as contribuições Programa Institucional de Bolsas de Iniciação à Docência subprojeto na área da Biologia (PIBID-BIO) da Universidade Estadual do Ceará (UECE) para a capacitação, formação inicial e continuada como docente, elencando também as relações entre teoria e prática associadas a Natureza da Ciência. Para isso, os bolsistas foram inseridos em uma das escolas parceiras do subprojeto, local em que esses desenvolveriam as atividades, bem como, a leitura de artigos referentes a Natureza das Ciências, a produção de resenhas acerca destes, e a realização de regências fundamentadas na NdC, como foco principal a delegar as relações teórico-práticas da docência. Com base na experiência efetivada, os autores afirmaram que as intervenções foram amplamente construtivas durante o processo de formação docente. Ao final das atividades propostas, perceberam a importância da teoria associada a prática na formação dos bolsistas. De acordo Ribeiro et al. (2018), durante as discussões da temática proposta em sala de aula, os estudantes mostraram-se bastante participativos, em razão da NdC despertar a curiosidade dos alunos, principalmente sobre as questões históricas, sociológicas e filosóficas de Biologia. As ações desenvolvidas no PIBID, também atentaram para a formação crítica dos bolsistas e futuros professores, permitindo a compreensão da necessidade de: planejamentos das aulas de Biologia, de forma a possibilitar a ampliação de conhecimentos; no aprimoramento de a práticas didático-pedagógica; aprendizagem acerca da postura adequada em sala de aula; percepção do espaço escolar como um ambiente de aprendizagem dinâmica de alunos e professores, inclusive professores em formação (RIBEIRO et al., 2018). Lima (2019), no artigo "A Natureza da Ciência e o ensino: investigando as percepções de futuros 
professores de química" investigou as concepções sobre Natureza da Ciência de licenciandos do curso de Química de uma universidade pública do estado da Paraíba, de modo a refletir sobre como esses conhecimentos poderiam modificar a postura do futuro professor em processo de formação. Por meio dos resultados obtidos, a autora verificou que alguns conhecimentos tradicionais permanecem enraizados na visão dos futuros professores, principalmente em relação as teorias a serem apresentadas como conhecimentos cumulativos e verdadeiros, além de atribuir ao método científico a essência da Ciência. De acordo com Lima (2019), os resultados evidenciaram a necessidade de modificar não apenas o ensino básico, mas também a construção dos conhecimentos formados nos cursos de licenciatura das Ciências naturais de modo a possibilitar aos licenciandos discutirem as suas práticas e conscientizar-se em relação as possíveis concepções epistemológicas presentes nas estratégias do ensino de Ciências.

\section{CONCLUSÕES}

Por meio deste estudo, percebeu-se um ínfimo número de pesquisas envolvendo a temática Natureza da Ciência ao longo das edições do CONAPESC e CONEDU. Ainda foi possível observar que os trabalhos publicados no evento estavam direcionados a investigar as concepções e percepções sobre a Natureza da Ciência em diferentes níveis de ensino. Diante disto, almeja-se que as produções desenvolvidas pelos autores e autoras, aqui divulgadas e discutidas, subsidiem o fortalecimento das discussões sobre a NdC, bem como, a proposição de materiais didáticos, abordagens de ensino, sequências de atividades, visando proporcionar aos alunos, seja da educação básica ou superior, uma visão dinâmica, problematizadora e mutável sobre a Ciência.

\section{REFERÊNCIAS}

CONCEIÇÃO, N. S.. Investigação da concepção dos alunos do ensino médio sobre os aspectos relacionados a natureza da ciência. In: CONEDU, 4. Anais. Campina Grande: Realize, 2017.

LIMA, B. T. S.. A natureza da ciência e o ensino: investigando as percepções de futuros professores de química. In: CONEDU, 4. Anais. Campina Grande: Realize, 2019.

MAIA, P. F.; JUSTI, R.. Conhecimentos de professores sobre Natureza da Ciência em contextos de modelagem: contribuições de atividades formativas. Revista Electrónica de Enseñanza de las Ciencias, v.19, n.3, 2020

MENDONÇA, P. C. C.. De que Conhecimento sobre Natureza da Ciência Estamos Falando? Ciência \& Educação, v.26, n.20003, p.1-16, 2020

MOUL, R. A. T. M. et al. Visões sobre a natureza da ciência: comparando concepções sobre cientistas de estudantes da educação básica. In: CONAPESC, 1. Anais. Campina Grande: Realize, 2016.
MOURA, B. A.. O que é natureza da Ciência e qual sua relação com a História e Filosofia da Ciência. Revista Brasileira de História da ciência, v.7, n.1, p.32-46, 2014.

MOURA, J. A.; VASCONCELOS, M. G. S.. Percepção dos bolsistas id do PIBID-BIO/FACEDI acerca da importância da abordagem da natureza da ciência (NDC) na educação científica. In: CONEDU, 4. Anais. Campina Grande: Realize, 2016.

RIBEIRO, R. L.; FEITOSA, E. M. A.. Relação teoria e prática e natureza da ciência: percepções a partir da experiência no PIBID-BIO/FACEDI. In: CONEDU, 5. Anais. Campina Grande: Realize, 2018.

SASSERON, L. H.. Ensino de Ciências por investigação e o desenvolvimento de práticas: uma mirada para a base nacional comum. Revista Brasileira de Pesquisa em Educação em Ciências, Rio de Janeiro, v.18, p.1-25, 2018.

SOUZA, R. S.. Discussões recentes na literatura sobre a natureza da ciência. In: CONAPESC, 2. Anais. Campina Grande: Realize, 2017.

A CBPC - Companhia Brasileira de Produção Científica (CNPJ: 11.221.422/0001-03) detém os direitos materiais desta publicação. Os direitos referem-se à publicação do trabalho em qualquer parte do mundo, incluindo os direitos às renovações, expansões e disseminações da contribuição, bem como outros direitos subsidiários. Todos os trabalhos publicados eletronicamente poderão posteriormente ser publicados em coletâneas impressas sob coordenação da Sustenere Publishing, da Companhia Brasileira de Produção Científica e seus parceiros autorizados. Os (as) autores (as) preservam os direitos autorais, mas não têm permissão para a publicação da contribuição em outro meio, impresso ou digital, em português ou em tradução. 